Santa Clara University

Scholar Commons

Psychology

College of Arts \& Sciences

$10-2002$

\title{
Recruitment of engaged couples for premarital counseling: An empirical examination of the importance of program characteristics and topics to potential participants
}

Kieran T. Sullivan

Santa Clara University, ksullivan@scu.edu

Carmen Anderson

Follow this and additional works at: http://scholarcommons.scu.edu/psych

Part of the Psychology Commons

\section{Recommended Citation}

Sullivan, K.T., \& Anderson, C. (2002). Recruitment of engaged couples for premarital counseling: An empirical examination of the importance of program characteristics and topics to potential participants. The Family Journal 10, 388-397.

http://doi.org/10.1177/106648002236757

This Article is brought to you for free and open access by the College of Arts \& Sciences at Scholar Commons. It has been accepted for inclusion in Psychology by an authorized administrator of Scholar Commons. For more information, please contact rscroggin@scu.edu. 
Running Head: RECRUITMENT OF ENGAGED COUPLES FOR COUNSELING

Recruitment of Engaged Couples for Premarital Counseling: An Empirical Examination of the Importance of Program Characteristics and Topics to Potential Participants

Kieran T. Sullivan

Santa Clara University

Carmen Anderson

Pepperdine University 
Recruitment of Engaged 3

The recent emphasis on prevention in helping couples to avoid marital distress may be limited by lack of participation in prevention programs by engaged couples. The purpose of this study is to understand what potential participants perceive are attractive characteristics in premarital prevention approaches. Eighty-six engaged couples completed questionnaires assessing demographics, personality and the relative importance of premarital program characteristics. The results indicate that leader characteristics, content, and topics such as communication, finances, and problem-solving are the most important elements of premarital counseling to couples. Differences based on gender and risk level are reported. Suggestions are made for more effective recruitment of couples for premarital counseling. 
Recruitment of Engaged 4

Recruitment of Engaged Couples for Premarital Counseling: An Empirical Examination of the Importance of Program Characteristics and Topics to Potential Participants 
Over the past two decades, there has been an increased emphasis on prevention by professionals who work with couples to help them maintain happy, stable marriages.

Researchers, practitioners, clergy, and others have developed and implemented programs designed to prevent marital distress and divorce (e.g., PAIRS, PREPARE, Relationship Enhancement; for a review see Silliman \& Schumm, 2000). Recent efficacy trials of such programs have been encouraging. For example, the premarital and relationship enhancement program (PREP), the most carefully investigated program to date, has been demonstrated to have positive effects on participant couples' relationships for up to five years following the program compared to control couples (Markman, Renick, Floyd, Stanley, \& Clements, 1993). The development and implementation of effective premarital prevention programs is important for several reasons, including the somewhat limited success rates of tertiary interventions (Jacobson \& Addis, 1993; Jacobson, Schmaling, \& Holtzworth-Monroe, 1987), the reluctance of distressed couples to seek marital therapy (Bradbury \& Fincham, 1990), and the considerable financial and emotional cost of marital distress and divorce to spouses and their children (Bloom, Asher, \& White, 1978 ; Coie et al., 1993; Halford \& Bouma, 1997).

While progress in the development and testing of premarital prevention programs is indeed encouraging, the effective use of these programs is limited, in part, by a lack of effective recruitment strategies. Ineffective recruitment strategies may result in low participation rates in community programs and could potentially affect efficacy research on premarital prevention programs by resulting in biased samples. With regard to participation in premarital counseling by couples in the community, it is clear that many, perhaps most, couples do not participate in premarital counseling. Participation rates have been reported between $33 \%$ and $66 \%$ in two different types of samples of newlywed couples (Sullivan \& Bradbury, 1997). In addition, 
couples who do participate may not be those who need the programs most. Silliman and Schumm (1995) surveyed 150 college students who had never been married about their attitudes regarding premarital counseling. They found that "those who typically might have problems ... appear to be those who shy away from premarital programming, even though they may be the ones who actually need it the most” (p. 47). This finding was confirmed using newlywed samples by Sullivan and Bradbury (1997). Newlywed couples were asked whether or not they participated in premarital counseling before their wedding. Couples who had participated were then compared with couples who had not participated on nine risk factors (factors that have been shown to predict future marital problems). Couples who had participated tended to be at relatively lower risk for future marital discord. Those who did not attend premarital counseling appeared to be the couples with the most risk factors (e.g., younger couples with lower incomes, less education, and higher levels of neuroticism and marital violence). 
The potential effects of ineffective recruitment on research are also of concern. There are several difficulties that arise in the area of efficacy research that may contribute to sample bias in these studies. First, there is evidence that the type of recruitment channel (e.g., newspaper advertisements, marriage licenses, etc.) can influence the make-up of the sample. In an empirical study examining the effects of different types of sampling techniques on samples obtained in marital research, Karney et al. (1995) found that a sample obtained via newspaper advertising was at much greater risk for future marital problems compared to a sample obtained via marriage licenses. Second, couples involved in studies evaluating prevention approaches who are assigned to the treatment group sometimes refuse the treatment, undermining researchers' efforts to employ random assignment ( $39 \%$ to $60 \%$ of couples refuse treatment across studies; see Markman, Floyd, Stanley, \& Lewis, 1986; Van Widenfelt, Hosmann, Schapp, \& Van der Staak, 1996; and Halford \& Behrens, 1996). Third, differential perceptions of risk between couples and researchers may lead to unexpected sample bias (Stein, Bauman, \& Ireys, 1991). As a result of these difficulties, it may be difficult to ascertain whether improvements in couples who receive prevention programs can be attributed to the program itself (rather than selective enrollment) and whether these improvements will generalize when the program is disseminated to the community. 
In order to improve participation rates in community programs and decrease sample bias in laboratory studies, it is important to understand what aspects of premarital counseling approaches are appealing to potential participants. Most premarital programs are developed based on what the provider knows or believes will prevent distress and divorce (e.g., psychological theories, research findings, counseling experience, etc.). These program characteristics, however sound, may or may not be characteristics that make premarital counseling programs attractive to engaged couples. Thus, the purpose of the present study is to investigate the characteristics of premarital counseling programs that are perceived as most important to engaged couples and those that are perceived as relatively unimportant to them. It is hoped that such information will be useful in forming recruitment strategies that will increase participation by couples. A second purpose is to examine whether there are any differences between higher and lower risk couples in perceptions of what is important in a premarital counseling program. 
The risk factors assessed in the current study are factors that have been identified empirically to predict future marital satisfaction and stability in previous, longitudinal studies on marriage. Demographic variables that have been demonstrated to predict future marital problems across studies include age at marriage, education and income (for a meta-analytic review of longitudinal studies on marriage, see Karney \& Bradbury, 1995). Neuroticism, a personality variable, was also assessed because it has been demonstrated to predict marital outcome across studies and over four decades of marriage (Kelly \& Conley, 1987). Finally, couples were asked whether or not they were currently living together, as cohabitation before marriage has been shown to predict marital instability over time (see Larson \& Holman, 1994 for an excellent review). Based on the research cited above, spouses are at higher risk when they are younger at marriage, have lower incomes and education levels, are more neurotic, and have cohabited before marriage. If couples who are at greater risk for future marital problems do have different perceptions about what is important in premarital counseling, it may be possible to design recruitment strategies specifically for them. 
Few studies of couples' preferences regarding characteristics of premarital counseling programs have been conducted. The studies that have been reported in the literature are based mostly on the perceptions of unmarried college students (e.g., Silliman \& Schumm, 1989; Silliman, Schumm, \& Jurich, 1992), convenience samples (e.g., Williams, 1992), or a combination of the two (e.g., Stucky, Eggeman, Eggeman, Moxley, \& Schumm, 1986). Because little is known about which characteristics are identified by engaged couples as important, the first phase of the study consisted of a series of focus groups as a first step in developing an instrument to assess the relative importance of program characteristics. Focus groups bring together a small number of participants from a well-defined target population to discuss a set of preselected topics under the guidance of a trained moderator (Merton, Fiske, \& Kendall, 1990; Morgan, 1996). For this phase of the study, groups of newlywed couples, some of whom participated in premarital counseling and some of whom had not, were brought together to discuss what attracted them (or what would have attracted them) to premarital counseling and what discouraged them (or would have discouraged them) from attending. The focus group responses were particularly useful in designing the questionnaire, not only in formulating the actual questions but also in fine-tuning the wording of particular questions to accommodate the “phraseology” that participants used to describe their experiences (O’Brien, 1993). 
In the second phase of the study, engaged couples were surveyed via mail using the newly-developed questionnaire. Participants rated the importance of four general areas: characteristics of the leader(s)/counselor(s), setting, content, and evidence of positive outcome. Participants were also invited to write in additional topics (not covered in the content section of the questionnaire) that they thought would be valuable or important to cover in premarital counseling. 
Because this research is exploratory in nature, specific hypotheses must be tentative. However, it is possible to derive some expectations based on the small number of published studies in this area. In the area of leader characteristics, two previous studies indicate that having a well-trained, professional provider is very important to participants (Silliman \& Schumm, 1995; Silliman et al., 1992). There is some evidence that programs run by married couples might be preferable to those run by individuals (Williams, 1992). In the area of setting, a small group format was found preferable in one study (Williams, 1992) whereas a therapist-couple format was preferred in another (Silliman et al., 1992). The importance of time spent in programs varies considerably among studies, with one reporting preference for brief programs (Silliman \& Schumm, 1995), another reporting that couples perceive longer programs as more effective (Stucky et al., 1986), and still another reporting that length of time as not important (Williams, 1992). In the area of content, both skill-building and insight-oriented content were reported as important by Silliman et al. Finally, in the area of outcome, Williams (1992) found that effectiveness is an important characteristic to engaged couples. 
To our knowledge, there is only one study to date that examined whether the characteristics of importance differed between higher-risk and lower-risk individuals. Silliman and Schumm (1995) found that lower-risk students (defined in their study as those with supportive family backgrounds) were willing to spend more time and money on premarital counseling compared to those who did not have supportive family backgrounds. 
There are also a few studies examining the relative importance of various topics that might be covered in premarital counseling. In one study, engaged couples were asked to write-in topics of interest (Williams, 1992), in others, individuals or couples who had already participated in premarital counseling were asked to rate the importance of a list of topics (Boisvert et al. 1992; Silliman \& Schumm, 1989; Russell \& Lyster, 1992; Williams, Riley, Risch, \& Van Dyke, 1999). Topics that emerged as important across studies included: communication skills, finances, conflict resolution, and children. Topics that emerged as unimportant across studies included: time management, chores, and family/friends. Topics that were rated as important in some studies but as not important in others included: sex, religion/spirituality, in-laws, and parenting.

Method

\section{Participants}

Eighty-six engaged couples participated in the study. In order to obtain a sample that was representative and had sufficient variance on the factors that predict future marital problems, several recruitment techniques were used. The recruitment area was defined as two major cities in Northern California. Participants were recruited via advertising in all local newspapers, in person at all bridal shows in both cities during the recruitment period, and via posters and pamphlets in every bridal store in the recruitment area (identified using the local phone book). To be eligible, couples had to be engaged, their wedding date had to be at least six months away, and they could not have already attended premarital counseling. 
Male participants' average age was $27.5(\mathrm{SD}=6.16$, range $=19-60)$ and they had received an average of $15.5(\mathrm{SD}=2.2)$ years of education, with $36 \%$ of the sample reporting less than 16 years of education. The average income for men was $\$ 30,000$ per year, the percent of men falling within income levels was as follows: $8 \%$ earned less than 10,000 per year, $16 \%$ earned between 10,001 and 20,000 per year, 26\% earned between 20,001 and 30,000 per year, 17\% earned between 30,000 and 40,001 per year, 8\% earned between 40,001 and 50,000 per year and $25 \%$ earned over 50,001 per year. It is important to note in evaluating these income levels, that the Silicon Valley, where these two cities are located, has for several years been the area with the highest cost of living in the United States. Seventy-seven percent of male participants were Caucasian, 9.5\% were Latino, 9.5\% were Asian, and 3.6\% were African- American. 
Female participants' average age was $26.2(\mathrm{SD}=4.86$, range $=19$ - 53) and they had received an average of $16(\mathrm{SD}=1.8)$ years of education, with $31 \%$ of the sample reporting less than 16 years of education. The average income for women was $\$ 20,000$ per year, the percent of women falling within income levels was as follows: $23 \%$ earned less than 10,000 per year, $18 \%$ earned between 10,001 and 20,000 per year, 20\% earned between 20,001 and 30,000 per year, 20\% earned between 30,000 and 40,001 per year, 5\% earned between 40,001 and 50,000 per year and 13\% earned over 50,001 per year. Sixty-one percent of female participants were Caucasian, $18.6 \%$ were Latina, $18.6 \%$ were Asian, and 2.3\% were African-American. 
Recruitment of Engaged 18

Experimenters verified participants' eligibility either over the phone, for those recruited via advertising, or in person at the bridal show. Couples provided contact information including their address, phone number, and the phone numbers of family members (for cases in which we lost contact with couples). Eligible couples were sent a packet in the mail that included the newly developed questionnaire assessing the importance of various characteristics of premarital counseling programs, a consent form, a demographic questionnaire, and questionnaires assessing risk for future marital problems.

Each participant was sent his or her own packet and self-addressed stamped return envelope to minimize the sharing of any information between partners. Couples were also instructed not to discuss answers with their partner until after they returned the packets. Participants were telephoned and reminded to return the packets if they had not done so within four weeks. Ninety-five eligible couples agreed to participate; eighty-six couples (91\%) returned full, completed packets. Once the experimenters received completed packets from both partners, couples were sent a check for \$25 and thanked for their participation.

\section{Questionnaires}

Demographics. The demographics questionnaire assessed participants' ages, ethnic identities, education levels, income levels, and whether or not they were currently living together.

Premarital Counseling. A series of focus groups was conducted with a separate sample of newlywed couples to assist in the development of a questionnaire designed to assess the relative importance of various premarital counseling program characteristics. Thirty-two newly married adults (16 couples) between the ages of 20 and 54 were chosen to participate after responding to newspaper advertisements and flyers. Participants were screened by telephone to ensure that they were married for less than one year and that they spoke English. Couples 
Recruitment of Engaged 19

participated in one of four focus groups. The first group consisted of couples who had received premarital counseling. The second group consisted of couples who had not received premarital counseling. The third and fourth groups were mixed regarding premarital counseling experiences; for these groups couples were split into an all-male group and an all-female group. The composition of the groups was designed to increase the homogeneity of each group, a traditional strategy used in focus group research. Perceived similarity of participants allows them to "spend less time explaining themselves to each other and more time discussing the issues at hand (Morgan \& Scannell, 1998). 
Recruitment of Engaged 20

Upon arrival, the couples were given a consent form for participating in a video-taped focus group and a statement of confidentiality. The groups began with detailed instructions, read verbatim by the group facilitator, explaining the purpose of the focus groups and rules for the upcoming discussion. Couples were asked to maintain confidentiality after leaving the group and were encouraged to participate equally in the discussion. Each group was then asked to discuss the following key questions: "What do you think is important to have a good marriage?" "Describe what you think would be important for a good premarital counseling program." “What were the reasons you did not receive premarital counseling?” (Groups 2-4). "What were the reasons you did receive premarital counseling?” (Groups 1,3,4). "What do you think would attract engaged couples to come to premarital counseling?” "What do you think are the most important reasons couples attend or don't attend premarital counseling?" "Name one thing that would probably make you go to premarital counseling." "Name one thing that would probably make you not go to premarital counseling.” Upon completion of the group, participants filled out demographic questionnaires and were then given $\$ 50$ compensation for their time. 
The videotapes were transcribed by undergraduate research assistants. All responses that were relevant to program characteristics were identified and the research team developed four broad categories that represented the domain of responses: leader characteristics, setting, content, and evidence of positive outcome. Individual items to assess each category were written based on the content and wording of responses by the focus group couples. The questionnaire was designed to assess how important each of the specific characteristics of premarital counseling would be in helping them to decide whether or not to go to premarital counseling. Items assessing the importance of leader characteristics included whether the leader was trustworthy, professional, experienced, a specific gender, or a couple rather than an individual leader. Items assessing the importance of the setting included location, amount of time spent in the program, and whether it was a group program or one-on-one counseling. Items assessing the importance of content included educational content (e.g., learning communication skills), practicing or roleplaying skills, and insight-oriented content (e.g., discussing personality, family backgrounds, etc.). Items assessing the importance of outcome included information about previous success rates of the program and information on whether other couples found it useful. Participants were asked to rate each characteristic scale of 1 (not very important) to 5 (very important). Reliability was adequate for this measure for men and women (Cronbach's alpha $=.70$ for men and .68 for women). See Appendix for a copy of the questionnaire. 
Neuroticism. Neuroticism was measured using the Neuroticism sub-scale of the Eysenck Personality Questionnaire (EPQ-N; Eysenck \& Eysenck, 1978). The EPQ-N is a 23-item, truefalse scale yielding a score from 0-23, with higher scores indicating higher levels of neuroticism. Example of items include “are you a worrier” and “are your feelings easily hurt?” Reliability scores were adequate for men (alpha $=.82)$ and for women $($ alpha $=.86)$. 
Results 
The mean ratings of the importance of program characteristics are shown in Table 1. Several leader characteristics were rated as either important or very important for the vast majority of engaged partners: 94\% of women and 93\% of men rated having a trustworthy leader as important or very important, $91 \%$ of women and $92 \%$ of men rated having a professional leader as important or very important, and $90 \%$ of women and $87 \%$ of men rated having an experienced leader as important or very important. Two content characteristics were also rated as important or very important by the majority of engaged partners: educational content (84\% of women and $76 \%$ of men) and insight-oriented content (79\% of women and $59 \%$ of men). Other program characteristics that were rated as important or very important by more than half the participants include: usefulness ratings by previous participants (60\% of women and $72 \%$ of men), location of the program (59\% of women and $61 \%$ of men), previous success rates of the program (59\% of women and 56\% of men), and the amount of time spent in the program (56\% of women, $58 \%$ of men). 
Five of the program characteristics that were assessed were not rated as important or very important by the majority of participants. Less than half of the women (37\%) and men (40\%) rated practicing or role-playing skills as important or very important. The opportunity to have group discussions was rated as important by less than half of the women (36\%) and men (28\%). The presence of other couples in the program (vs. working alone with a leader) was also rated as important by very few women (21\%) and men (17\%). Two leader characteristics were not rated as important by the vast majority of participants: couple leaders (vs. individual leaders) were rated as important or very important by only $15 \%$ of the women and $21 \%$ of the men, and the gender of the leader was rated as important or very important by only $9 \%$ of the women and $15 \%$ of the men.

Paired samples t-tests were run to determine whether there were significant gender differences in ratings of program characteristics. The results can be seen on Table 1 . One program characteristic, insight-oriented content (described as discussing personality, family backgrounds, etc.) was significantly different for women and men, with women $(\underline{\mathrm{M}}=4.14)$ rating insight-oriented content as significantly more important than men $(\underline{\mathrm{M}}=3.76), \underline{\mathrm{t}}=2.83$, $\underline{\mathrm{p}}$ $<.01{ }^{1}$ There were no other significant differences between women and men in their ratings of the importance of program characteristics.

Correlational analysis were conducted to determine whether age, income, education, and neuroticism were significantly related to ratings of importance of program characteristics. There were no significant correlations between age or income and ratings of the characteristics. Education was negatively related to the importance of practicing or role-playing skills for men, such that men who were more educated were less likely to rate skills rehearsal as important, $\underline{r}=$ $.23, \mathrm{p}<.05$. Women's scores on the neuroticism scale were negatively correlated to their ratings of the importance of having a professional leader, such that the higher women scored on the neuroticism scale, the less likely they were to rate having a professional leader as important, $\underline{r}=$ - 
$.29, \mathrm{p}<.01$. Finally, women's neuroticism scores were positively related to their ratings of the importance of discussions with other couples, such that the higher women scored on neuroticism the more likely they were to rate discussions with other couples as important, $\underline{\mathrm{r}}=.38, \underline{\mathrm{p}}<.01$. Independent samples t-tests were run to determine whether engaged couples who were currently living together rated program characteristics differently compared to engaged couples who were not living together (see Table 2). Fifty-two percent of the couples reported that they were living together, $48 \%$ reported that they were not living together. Four characteristics were rated significantly different by women who were living with their fiances compared to women who were not currently living with their fiances. Women who were currently living with their fiances were less likely to rate having a professional leader as important, compared to women who lived apart from their fiances. Women who were currently living with their fiances were also less likely to rate having an experienced leader as important, compared to women who lived apart from their fiances. Educational content was rated as more important to women who were currently living with their fiances compared to women who lived apart from their fiances. Finally, the importance of attending with a group of couples was less important among women who were currently living with their fiances compared to women who lived apart from their fiances. No significant differences were found between men who lived with their fiances and men who did not.

Additional topics were written in by men and women as important or valuable for premarital counseling (see Table 3). Forty-nine distinct topics were identified among the responses. Only one topic, communication, was written in by more than half the participants, and only by women (written in by $59 \%$ of women and $38 \%$ of men). Two additional topics were written in by more than one-third of the women, finances (36\% of women and $27 \%$ of men) and problem-solving (33\% of women and $22 \%$ of men). Of the remaining 46 topics, only 7 were written in by at least $10 \%$ of the women or men. The topic having children was written in by $16 \%$ 
of the women and $12 \%$ of the men. Topics written in as important by more than 10 percent of women but not by more than 10 percent of men included expectations (21\% of women), family of origin issues (19\% of women), parenting skills (16\% of women), religion (14\% of women), and goals (11\% of women). Sex was written in as important by more than $10 \%$ of the men (11\%), but not by more than $10 \%$ of the women.

\section{Discussion}

When asked to rate the importance of program characteristics for premarital counseling programs, engaged couples clearly perceived some characteristics as quite important and others as not important at all. Couples appeared to be most concerned with the characteristics of the leader and the content of the program. Working with a trustworthy, professional, and experienced leader is clearly critical for men and women in considering premarital counseling programs. Finding a program that is educational and insight oriented also appears to be of considerable importance to couples. These findings support previous findings that having a welltrained, professional provider is very important to potential participants as is insight-oriented content (Silliman \& Schumm, 1995; Silliman et al., 1992). Evidence that the program is effective, such as usefulness ratings by previous participants and previous success rates of the program, also appeared to make potential programs more attractive to couples, consistent with Williams’ (1992) finding that effectiveness is an important characteristic to couples.

Characteristics that make the program more convenient, such as location and the amount of time spent in the program, are also considered important, though less so than leader and content characteristics.

Some characteristics, however, were clearly not important to the majority of couples. Couples are relatively unenthused about the inclusion of practicing and role-playing skills or group discussions during the program. In addition, the gender of the leader, or whether the leader was an individual or a couple, do not appear to matter much to the couples. These 
findings indicate that the results of previous studies assessing college students may not always be consistent with what engaged couples with a wide range of educational backgrounds believe to be of importance in making their decisions to participate in premarital counseling programs.

The most striking finding regarding perspectives based on gender is that men and women generally agree on the importance of different aspects of premarital counseling programs. Of the fourteen characteristics, men and women rated thirteen similarly. The only significant gender difference was for the characteristic of insight-oriented counseling. Women clearly regard the inclusion of insight-oriented approaches as more important compared to men. This finding is consistent with Silliman and Schumm’s (1995) study which reported that females enjoy programs that are in-depth more than males do.

There were several differences in the importance of characteristics when comparing highrisk and low-risk couples, though the impact of risk status on importance ratings was different for men and women. Women's ratings were much more likely to vary as a result of risk status compared to men. For men, the only significant difference was that men with less education tended to rate the inclusion of practice and role-playing skills as more important. Higher risk women were less likely to rate having a professional, experienced leader, including educational content, and using a group format as important, compared to women of lower risk. Higher risk women were more likely to rate discussions with other couples as important compared to lower risk women.

The topics that were written in by men and women as important or valuable for premarital counseling programs were strikingly similar to those reported in previous studies (Boisvert et al., 1992; Russell \& Lyster, 1992; Silliman \& Schumm, 1989; Williams et al., 1999). The topics of importance for men and women were exactly those that were found in previous studies: communication skills, finances, conflict resolution, and having children. Topics that were rated as important in some previous studies but not others, such as sex, religion, and 
parenting, were differentially written in by men and women in the current study. This suggests that the ambiguity of previous findings might be due to gender differences in perceptions of importance. The current findings suggest that religion and parenting skills are perceived as important topics more often by women, whereas sex is perceived as an important topic more often by men. Apparent gender differences must be interpreted with caution, however, as women tended to write in more topics overall compared to their husbands.

It is important to note several characteristics of the current study that may limit the usefulness of the findings. First, though variability on risk factors made it possible to study differences based on risk, measures of central tendency indicated that the sample as a whole was older and slightly more educated compared to samples from comparable studies and national statistics (e.g., Karney et al., 1995) In addition, though the ethnic diversity of the sample is greater than typical studies on marriage, over $60 \%$ of the sample was Caucasian. These sample biases must be taken into consideration when applying the current findings.

With regard to the findings comparing couples at greater and lesser risk, it is certainly possible that the lack of differences found in the current study may be due to the particular variables used to assess risk. Though these variables were chosen because previous studies provided support that they were predictive of future marital problems, the identification of such predictor variables is an ongoing effort in the literature on marriage. It is certainly possible that the use other potential "risk" variables may have revealed greater differences between higher risk and lower risk couples. In any case, the identification of risk variables and the use of such variables in research of this nature certainly deserves additional attention in the literature.

It is also important to highlight that the current findings reflect only the perceptions of couples regarding the importance of various program or counseling characteristics. It seems likely that these perceptions are only one element that influence couples’ decisions about whether to participate in premarital counseling. Other important variables that influence couples' 
actual behavior may include the perceptions and behavior of significant others, the beliefs and expectations about the costs and benefits of premarital counseling, and the extent to which couples believe themselves to be vulnerable to future marital problems. Recently, models have begun to emerge from other areas of research, such as the health prevention literature, that may be very useful in studying these additional variables and how they might affect couple’s decisions to participate in premarital prevention programs (e.g., the health belief model). Additional research into these areas would help to further clarify effective recruitment strategies and is currently being conducted. However, based on the present study, some suggestions for recruitment can be made.

Implications for the Recruitment of Engaged Couples for Premarital Counseling

Emphasize the elements of your program or counseling approach that appeal to couples. Designing programs solely on what couples perceive to be important without taking into account research findings and clinical experience may not actually serve couples well. The purpose of this paper is not to suggest program or counseling protocols based on couple’s perceptions. However, it does make sense to emphasize the elements of your prevention approach that are consistent with what we know attracts couples to engage in premarital prevention.

The importance of leader characteristics. Perhaps the most consistent finding, in the current study and in studies of varying sample types, is the importance of leader characteristics. Specifically, couples perceive a professional, trustworthy leader as the most important among all the program characteristics rated. Therefore it will be important, when recruiting couples, to present the credentials, experience, and principles (e.g., respects confidentiality) of the leader or leaders.

Emphasize educational content. After having a professional leader, educational content was the most important characteristic to couples in the current study. Men and women endorse educational content as important, whereas insight-oriented approaches and skills rehearsal are 
perceived differently and as less important overall. While there is evidence to suggest that insight-oriented approaches and skills rehearsal may benefit couples, these elements are probably not the ones to emphasize in the beginning stages of recruiting couples.

Acknowledge the gender differences in perceptions of importance. It appears that women perceive insight-oriented treatment and discussion of related topics such as families of origin and expectations about marriage as more important compared to men. Women also endorse the topics of parenting skills and religion at a much higher rate than men. Translating these differences into recruitment strategies can be tricky, however. If you have evidence that targeting a specific gender may help increase recruitment (e.g., wives often seem to bring their reluctant husbands in, or husbands often refuse to go despite wives’ encouragement) it may make sense to emphasize characteristics and topics that appeal to that gender. Of course, participation in premarital counseling requires some minimal level of willingness from both partners, so it may be a mistake to emphasize strategies designed for only one of them.

Be sure to include the "Big Four" topics. The finding that men and women find communication, finances, problem-solving, and having children to be the most important topics has been replicated many times. Thus, including these four topics and letting couples know up front that they will be addressed, may help recruitment efforts.

Consider making evidence of effectiveness available to potential participants. The idea of providing evidence of effectiveness appears to appeal a great deal to engaged couples. The majority of men and women endorsed items such as knowing the previous success rates of the program (or counselor) and usefulness ratings by previous participants as important or very important. Consider collecting this kind of outcome data, and perhaps testimonials from previous participants as well, and making it available to potential participants.

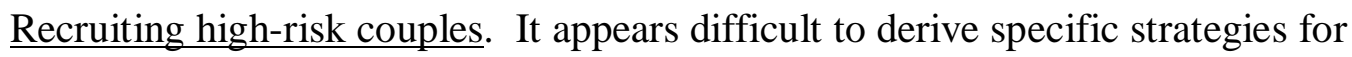
recruiting higher-risk couples based on the current findings. Perceptions of the relative 
importance of program characteristics varied based on risk much more for women than for men, and higher-risk men's perceptions were different than higher-risk women’s perceptions. It is notable, however, that there were no differences in perceptions based on age or income, indicating that similar strategies may be used for young and low income couples as are used for older, higher income couples. It does appear that use of practice and skills rehearsal appeals particularly to less educated men and that leader characteristics are less important and the presence of peers more important for more neurotic women compared to less neurotic women. Overall, however, the most striking finding is the lack of differences found between couples of higher-risk status compared to couples of lower-risk status. These may indicate that no special recruitment strategies are needed for higher-risk couples or that we have yet to identify critical areas of difference that can inform our recruitment strategies. Further research is clearly warranted to clarify this issue. 


\section{Reference}

Bloom, B.L., Asher, S.J.,\& White, S.W. (1978). Marital disruption as a stressor: A review and analysis. Psychological Bulletin, 85, 867-894.

Boisvert, J.M., Ladouceur, R., Beaudry, M., Freeston, M.H., Turgeon, L., Tardif, C., Roussy, A., Loranger, M. (1992). Perception of marital problems and of their prevention by Quebec young adults. The Journal of Genetic Psychology, 156, 33-44.

Bradbury, T.N., \& Fincham, F. D. (1990). Preventing marital dysfunction: Review and analysis. In F.D. Fincham \& T.N. Bradbury (Eds.), The psychology of marriage: Basic issues and applications (pp. 375-401). New York: Guilford Press.

Coie, J.D., Watt, N.F., West, L.G., Hawkins, J.D., Asarnow, J.R., Markman, H.J., Ramey, S.L., Shure, M.B., \& Long, B. (1993). The science of prevention: A conceptual framework and some directions for a national research program. American Psychologist, 48, 1013-1022.

Eysenck, S.B., \& Eysenck, H.J. (1978). Impulsiveness and venturesomeness: Their position in a dimensional system of personality description. Psychological Reports, 43, 1247-1255.

Halford, K.W., \& Behrens, B. (1996). Prevention of marital difficulties. In P. Cotton \& H.J. Jackson (Eds.), Early intervention and preventive mental health applications of clinical psychology. Melbourne: Australian Psychological Society.

Halford, K.W. \& Bouma, R. (1997). Individual psychopathology and marital distress. In K.W. Halford \& H.J. Markman (Eds.), Clinical handbook of marriage and couples interventions (pp. 291-321). New York, NY: Wiley.

Jacobson, N.S., \& Addis, M.E. (1993). Research on couples and couples therapy: What do we know, where are we going? Journal of Consulting and Clinical Psychology, 61, 85-93. Jacobson, N.S., Schmaling, K.B., \& Holtzworth-Monroe, A. (1987). Component analysis of behavioral marital therapy: Two year follow-up and prediction of relapse. Journal of Marital and Family Therapy, 13, 187-195. 
Karney, B.R., Davila, J., Cohan, C.L., Sullivan, K.T., Johnson, M.D., \& Bradbury, T.N. (1995). An empirical investigation of sampling strategies in marital research. Journal of Marriage and the Family, 57, 909-920.

Karney, B.R., \& Bradbury, T.N. (1995). The longitudinal course of marital quality and stability: A review of theory, method, and research. Psychological Bulletin, 118, 3-34.

Kelly, E.L., \& Conley, J.J. (1987). Personality and compatibility: A prospective analysis of marital stability and marital satisfaction. Journal of Personality and Social Psychology, 52, 27-40.

Larson, J.H. \& Holman, T.B. (1994). Premarital predictors of marital quality and stability. Family Relations, 43, 228-237.

Markman, H.J., Renick, M.J., Floyd, F.J., Stanley, S.M., \& Clements, M. (1993). Preventing marital distress through communication and conlict management training: A 4- and 5year follow-up. Journal of Consulting and Clinical Psychology, 61, 70-77.

Markman, H.J., Floyd, F.J., Stanley, S.M., \& Lewis, H.C. (1986). Prevention. In N.S. Jacobson \& A.S. Gurman (Eds.), Clinical handbook of marital therapy (pp. 173-195). New York: Guilford Press.

Merton, R.K., Fiske, M., Kendall, P.L. (1990). The Focused Interview (2 ${ }^{\text {nd }}$ ed.) New York: Free Press.

Morgan, D.L. (1996). Focus Groups. Annual Review of Sociology, 22, 129-152.

Morgan, D.L. \& Scannell, A.U. (1998). Planning Focus Groups. Thousand Oaks, CA: Sage. O’Brien, K.J. (1993). Improving survey questionnaires through focus groups. In D.L. Morgan (Ed.), Successful focus groups: Advancing the state of the art (pp. 105-117). Thousand Oaks, CA: Sage.

Russell, M.N., \& Lyster, R.F. (1992). Marriage preparation: Factors associated with consumer 
satisfaction. Family Relations, 4, 446-452.

Silliman, B., \& Schumm, W.R. (1989). Topics of interest in premarital counseling. Journal of Sex and Marital Therapy, 15, 23-30.

Silliman, B., \& Schumm, W.R. (1995). Client interests in premarital counseling: A further analysis. Journal of Sex and Marital Therapy, 21, 43-56.

Silliman, B., \& Schumm, W.R. (2000). Marriage preparation programs: A literature review. The Family Journal: Counseling and Therapy for Couples and Families, 8, 133-142

Silliman, B., \& Schumm, W.R., \& Jurich, A.P. (1992). Young adults’ preferences for premarital preparation program designs: An exploratory study. Contemporary Family Therapy, 14, 89-100.

Stein, R.E.K., Bauman, L.J., \& Ireys, H.T. (1991). Who enrolls in prevention trials? Discordance in perception of risk by professionals and participants. American Journal of Community Psychology, 19, 603-617.

Stucky, F., Eggeman, K., Eggeman, B.S., Moxley, B., \& Schumm, W.R. (1986). Premarital counseling as perceived by newlywed couples: An exploratory study. Marital Therapy, 12, 221-228.

Sullivan, K.T., \& Bradbury, T.N. (1997). Are premarital prevention programs reaching couples at risk for marital dysfunction? Journal of Consulting and Clinical Psychology, $\underline{65}$, 24-30.

Van Widenfelt, B., Hosmann, C., Schapp, C., \& Van der Staak, C. (1996). The prevention of relationship distress for couples at risk: A controlled evaluation with nine-month and two-year follow-ups. Family Relations, 45, 156-165.

Williams, L.M. (1992). Premarital counseling: A needs assessment among engaged individuals. Contemporary Family Therapy, 14, 505-518.

Williams, L.M., Riley, L.A., Risch, G.S., \& Van Dyke, D.T. (1999). An empirical approach to designing marriage preparation programs. The American Journal of Family Therapy, 27, 
271-283. 


\section{Footnotes}

${ }^{1}$ The probability of one Type I error when conducting 14 tests with an alpha level of .01 is $14 \%$. Therefore it is possible, though not likely, that the significant difference between men and women on ratings of the importance of insight-oriented therapy is simply due to chance. 


\section{Authors' Note}

This research was funded by a Thomas Terry Research Grant from Santa Clara

University awarded to Kieran Sullivan. The authors would like to thank Neda Raymond, Kristy Marines, and Trisha Mlnarik for their assistance on this project and Eleanor Williamsen, Lauri Pasch, and four anonymous reviewers for feedback on earlier versions of the manuscript. Correspondence regarding this article may be sent to Kieran Sullivan, Ph.D., Department of Psychology, Santa Clara University, Santa Clara, CA 95124 or by email to ksullivan@scu.edu. 


\section{Appendix}

The following are aspects of premarital counseling programs. Please circle how important each aspect would be to you in choosing a program?

$\begin{array}{cc}\text { Not very } & \text { Very } \\ \text { important } & \text { important }\end{array}$

Characteristics of Leader(s)/Counselor(s)

Trustworthy

Professional

Experienced

Gender of leader/counselor

A couple rather than an individual

$\begin{array}{lllll}1 & 2 & 3 & 4 & 5 \\ 1 & 2 & 3 & 4 & 5 \\ 1 & 2 & 3 & 4 & 5 \\ 1 & 2 & 3 & 4 & 5 \\ 1 & 2 & 3 & 4 & 5\end{array}$

Setting

$\begin{array}{lllllll}\text { A group of couples (vs. just you and your fiance) } & 1 & 2 & 3 & 4 & 5\end{array}$

$\begin{array}{lllllll}\text { Location (Proximity to work or home) } & 1 & 2 & 3 & 4 & 5\end{array}$

$\begin{array}{lllllll}\text { Amount of time spent in program } & 1 & 2 & 3 & 4 & 5\end{array}$

\section{Content}

$\begin{array}{lllllll}\text { Educational (e.g., learning communication skills) } & 1 & 2 & 3 & 4 & 5\end{array}$

Practicing or role-playing skills

$\begin{array}{lllll}1 & 2 & 3 & 4 & 5\end{array}$

Insight-oriented (e.g., discussing personality, family backgrounds, etc.)

$\begin{array}{lllll}1 & 2 & 3 & 4 & 5 \\ 1 & 2 & 3 & 4 & 5\end{array}$

Discussions with other couples

\section{Outcome}

Previous success rates of the program/person

$\begin{array}{llll}1 & 2 & 3 & 4\end{array}$ 5

Information on whether other couples have found the program useful

$\begin{array}{lllll}1 & 2 & 3 & 4 & 5\end{array}$


What kinds of topic would be valuable and important to cover in premarital counseling? 


\section{Biographical Statements of the Authors}

Recruitment of Engaged 41

Kieran T. Sullivan received her Ph.D. in psychology from the University of California, Los Angeles, in 1997. She is an assistant professor in the Department of Psychology at Santa Clara University in California. Her recent research has focused on increasing the effectiveness of prevention approaches for marital problems, specifically studying implementation, recruitment, and the use of para-professionals in premarital counseling. She has also written articles on couples therapy and factors that may impact the future satisfaction of couples, such as social support in marriage and religiosity. Clinically, Dr. Sullivan’s focus has been on helping couples to maintain happy marriages, using both prevention approaches and traditional marital therapy.

Carmen Anderson received her Bachelor's degree in Psychology from Santa Clara University in 2001. She is currently a graduate student at Pepperdine University in California and will graduate with her M.A. in Clinical Psychology in 2003. Her current research interests include determining which factors motivate couples to attend premarital counseling and the significance of spirituality and the therapeutic relationship. Clinically, Ms. Anderson is interested in couples therapy and therapy with persons infected with HIV/AIDS. 
Recruitment of Engaged 
March 25, 2002 
The Family Journal

C/O Mary Kay Nieponski

16443 South Parker Road

Lockport, IL 60441-9748

Dear Mary Kay,

Thank you very much for all your assistance with our manuscript "Recruitment of engaged couples for premarital counseling: An empirical examination of the importance of program characteristics and topics to potential participants." We are very excited to hear that it will appear in the October 2002 issue of The Family Journal.

As you suggested, I have made a few changes based on the suggestions of one reviewer. I have enclosed two copies of the final version of the manuscript, along with a matching disk. Please note that the manuscript is in WordPerfect and the tables are in Excel. Let me know if this presents any difficulties.

I have also enclosed the author information form for myself. My co-author will forward hers shortly. Please be kind enough to send an email confirming receipt of this final version to ksullivan@scu.edu.

Thank you again for all your assistance. It has been a pleasure working with you.

Sincerely,

Kieran Sullivan, PhD 